\title{
Investigation on influence of cutting parameters on spindle vibration of CNC wood milling machine
}

\author{
Van Thuy Tran ${ }^{1}$ and Huu Loc Nguyen ${ }^{2}$ \\ ${ }^{1}$ Faculty of Mechanical Engineering, HCMC University of Technology, VNU-HCM, Viet Nam (PhD. Student) \\ ${ }^{2}$ Faculty of Mechanical Engineering, HCMC University of Technology, VNU-HCM, Viet Nam
}

\begin{abstract}
In machining operation, the cutting parameters greatly influences on the spindle vibration of a CNC wood milling machine. The paper presents the effect of the cutting parameters such as feed rate, cutting speed, and cutting depth on the vibration amplitude of the spindle when machined on CNC milling machine using Box-Hunter method of experimentation. The lowest natural frequency of this machine is $250 \mathrm{~Hz}$. Experimental results have established a second-order regression equation that demonstrates the effect of three parameters such as feed rate, cutting speed, and cutting depth on the vibration amplitude of the spindle. From that base, determine the most reasonable cutting parameters when machining on CNC wood milling machines so that the spindle vibration amplitudes is minimal. In addition, The comparison results show that the spindle head vibration amplitude of the machine using the bolt joint is larger than the spindle head vibration amplitude of the machine using the weld joint
\end{abstract}

\section{Introduction}

Traditionally, the base and other major components of a machine tool have been made of gray or nodular cast iron, which has the advantages of low cost and good damping, but the disadvantage of heavy weight

In modern machine design, lightweight structures are desirable because of ease of transportation, higher natural frequencies, and lower inertial forces of moving members. Lightweight designs are a basic goal in machine tool design and require fabrication processes such as mechanical fastening (bolts and nuts) of individual components and welding. Bolted and welded machine tool structures consists of pre-cut stock materials such as plates, tubes, channels, and angles which are joined together to form the structure in Fig.1. Such stock items are available in a wide range of sizes and shapes and have some highly desirable mechanical properties such as formability, machinability and weldability. Of special interest are round and rectangular tubes whose closed cross sections have a very high stiffness-to-weight ratio [1].

Welded machine tool structures provide easy scalability in terms of size and outstanding flexibility in terms of fast design and fabrication; however, damping of the structure is a very critical issue. Unlike cast iron or polymer concrete-based components, welded steel plates have virtually no internal damping and are therefore prone to unwanted vibrations. Despite the shortcomings listed above, designing and building a machine as a welded structure has the big advantage of a much lighter design with a substantially shorter lead time compared to a cast design.

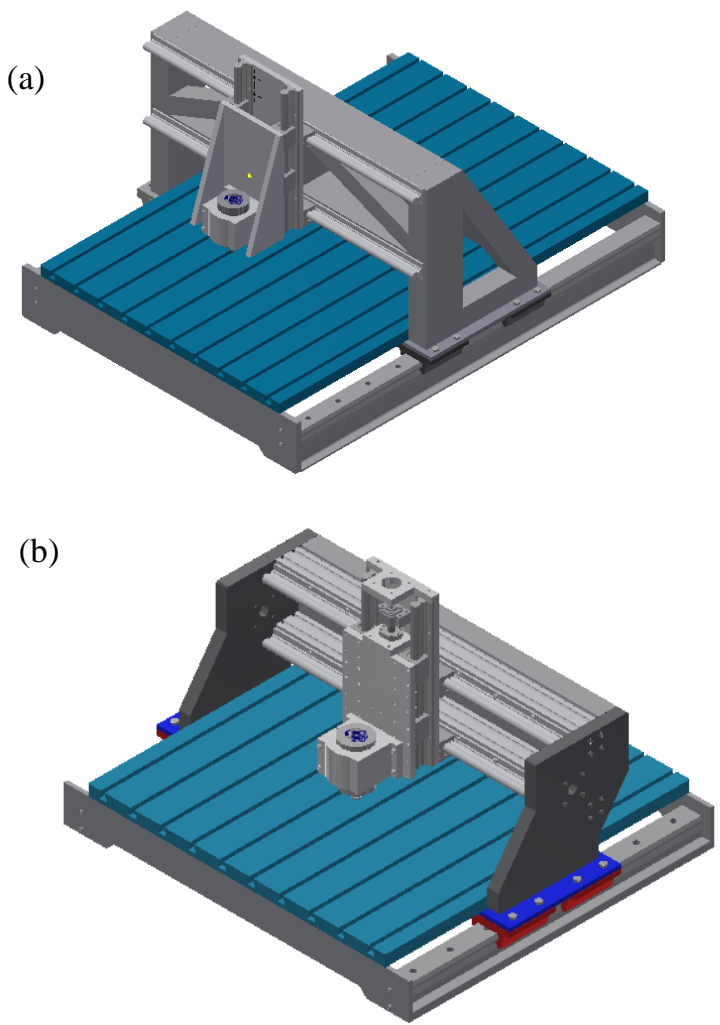

Figure 1. The CNC machine tool structures: (a) Welded structure and (b) Bolted structure 
The vibrations are induced due to machine faults, cutting parameters, cutting tool, work piece deformation, etc. Cutting parameters especially feed rate, depth of cut and spindle speed if not properly controlled can increase the vibration in the machining process. Too high vibration is very dangerous and may lead to serious injury. Therefore, vibration must be minimized to stabilize the cutting process, improve surface roughness and prevent tool from breaking. The effect of cutting tool vibration on surface roughness of workpiece in dry turning operation and a correlation between surface roughness and cutting tool vibration in turning [2]. Forced and self-excited vibration limits the stability of cutting and lead to tool and machine damage. It also limits the productivity of machining operation.

Controlling spindle vibration of machine tool is one of the approaches for enhancing the quality of the product. Investigated the Effect of spindle forced vibrations on surface roughness, dimensional accuracy, and tool wear in vertical milling of AISI P20 [3]. Several researchers have studied the effect of cutting parameters such as spindle speed, feed rate, axial and radial depth of cut, appropriate selection of tool material and tool geometry in machining of aluminum based alloys $[4,5]$ Prediction of surface roughness in end face milling based on Gaussian process regression and cause analysis considering vibration of cutting tool [6]. Developed experimental plan and conducted experiments based on central composite design (CCD) of response surface methodology (RSM) [7]. Experimental investigation on the effect of cutting parameters on the spindle vibration and surface roughness in the precision end-milling process using the singular spectrum analysis [8-10]. An experimental investigation on the effect of machining and geometrical parameters such as spindle speed, feed rate, axial and radial depth of cut and radial rake angle on responses during end milling operation on the surface roughness and its defects of AL 6061-T6 [11]. Effect of tool vibration, cutting conditions on surface roughness during lathe dry turning process $[12,13]$

Surface roughness is mainly affected by machine tool vibration. To improve the surface roughness, it is very essential to know the influences of cutting parameters on machine tool vibration. The purpose of this research is to investigate on the influences of cutting parameters such as feed rate, cutting speed and cutting depth on spindle vibration amplitude of welded structure of CNC wood milling machine structure using Box-Hunter quadratic experimental model.

\section{Experimental methodology}

\subsection{Experimental setup}

The experiments have been performed on welded structure of CNC wood milling machine. The lowest natural frequency of this machine is $250 \mathrm{~Hz}$. The device used for the spindle vibration test of CNC milling machine consists of instrument accelerometer sensor PCB 603C01, PCB Group, the accelerometer sensitivity $10.2 \mathrm{mV} / \mathrm{g}$. The Multi-Channel NI SCXI-1000DC System was used to analyze the vibration detected by the accelerometer. For a good operating of the NI SCXI1000DC system, the NI Signal Express software displayed the result of vibration data and a personal computer. The workpiece material used in this study is fir wood. The experimental setup for operation is shown in Fig.2. In particular, the acceleration sensor is attached to the spindle head of the machine, the NI SCXI-1000DC measurement device is connected to the acceleration sensor and the computer. Measurement data is collected and displayed through the NI Signal Express software.
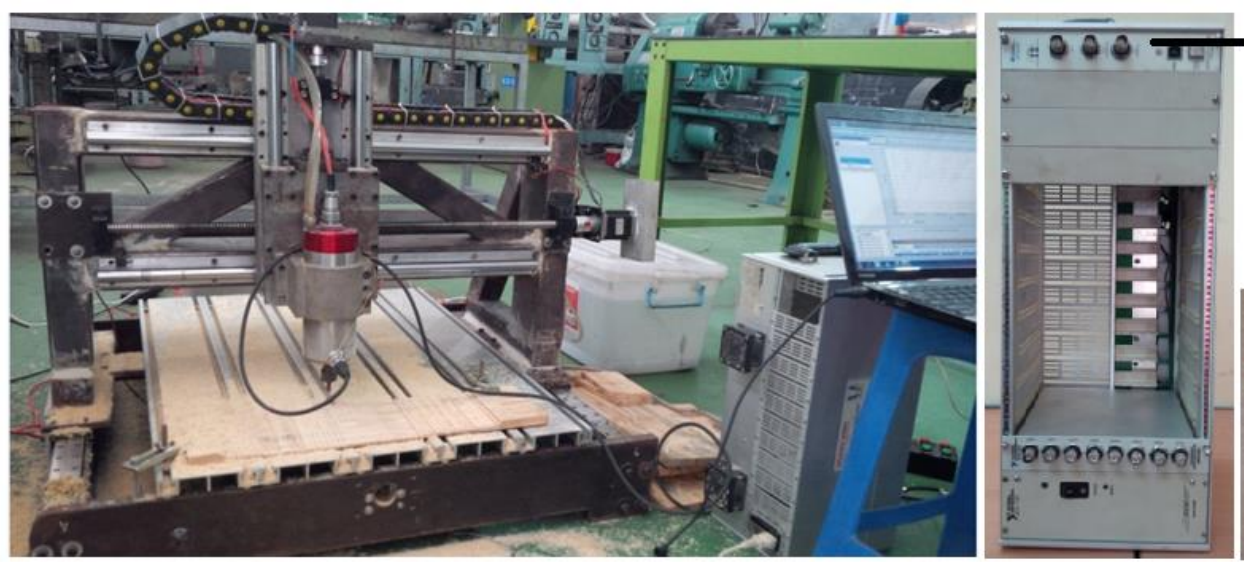

Multi-Channel

Figure 2. Experimental Setup

\subsection{Design of Experiment (DOE)}

The machining parameters were selected are spindle speed, feed rate and depth of cut. Cutting parameters were considered as input factors, spindle vibration were considered as output parameters during this analysis. The number of levels for each factors considered in this DOE is as shown in Table 1.

Experimental matrix based on the symmetrically mixed quadratic planning model with 3 coded factors as shown in Table 2. 
Table 1. Design schema of cutting parameters and their levels

\begin{tabular}{|c|c|c|c|c|c|c|c|c|}
\hline \multirow{2}{*}{$\begin{array}{l}\text { Variables or } \\
\text { parameter }\end{array}$} & \multicolumn{2}{|c|}{ Factor symbol } & \multirow{2}{*}{$\begin{array}{c}\text { interval of } \\
\text { variation }\end{array}$} & \multicolumn{5}{|c|}{ Variable range of cutting parameters } \\
\hline & $\begin{array}{l}\text { Actual } \\
\text { factor }\end{array}$ & $\begin{array}{l}\text { Code } \\
\text { factor }\end{array}$ & & $\begin{array}{l}\text { level } \\
-\alpha\end{array}$ & $\begin{array}{l}\text { level (- } \\
\text { 1) }\end{array}$ & $\begin{array}{c}\text { level } \\
(0)\end{array}$ & $\begin{array}{c}\text { level } \\
(+1)\end{array}$ & $\begin{array}{l}\text { level } \\
+\alpha\end{array}$ \\
\hline $\begin{array}{c}\text { Spindle Speed } \\
{[\mathrm{rev} / \mathrm{min}]}\end{array}$ & $\mathrm{n}$ & $\mathrm{x}_{1}$ & 5000 & 2590 & 6000 & 11000 & 16000 & 19410 \\
\hline Depth of Cut [mm] & $\mathrm{t}$ & $\mathrm{x}_{2}$ & 0.6 & 0.29 & 0.7 & 1.3 & 1.9 & 2.31 \\
\hline $\begin{array}{l}\text { Feed Rate } \\
{[\mathrm{mm} / \mathrm{min}]}\end{array}$ & $\mathrm{s}$ & $\mathrm{x}_{3}$ & 500 & 159 & 500 & 1000 & 1500 & 1841 \\
\hline
\end{tabular}

Table 2. Experimental matrix of 3 factors

\begin{tabular}{|c|c|c|c|c|c|c|c|c|c|c|c|}
\hline & $\mathbf{N}^{\mathbf{0}}$ & $\mathbf{x}_{\mathbf{0}}$ & $\mathbf{x}_{\mathbf{1}}$ & $\mathbf{x}_{\mathbf{2}}$ & $\mathbf{x}_{\mathbf{3}}$ & $\mathbf{x}_{\mathbf{1}} \mathbf{x}_{\mathbf{2}}$ & $\mathbf{x}_{\mathbf{1}} \mathbf{x}_{\mathbf{3}}$ & $\mathbf{x}_{\mathbf{2}} \mathbf{x}_{\mathbf{3}}$ & $\mathbf{x}_{\mathbf{1 1}}$ & $\mathbf{x}_{\mathbf{2 2}}$ & $\mathbf{x}_{\mathbf{3 3}}$ \\
\hline Number of & 1 & +1 & +1 & +1 & +1 & +1 & +1 & +1 & +1 & +1 & +1 \\
experi- & 2 & +1 & -1 & +1 & +1 & -1 & -1 & +1 & +1 & +1 & +1 \\
ments in & 3 & +1 & +1 & -1 & +1 & -1 & +1 & -1 & +1 & +1 & +1 \\
nucleus & 4 & +1 & -1 & -1 & +1 & +1 & -1 & -1 & +1 & +1 & +1 \\
$2^{k}$ & 5 & +1 & +1 & +1 & -1 & +1 & -1 & -1 & +1 & +1 & +1 \\
& 6 & +1 & -1 & +1 & -1 & -1 & +1 & -1 & +1 & +1 & +1 \\
& 7 & +1 & +1 & -1 & -1 & -1 & -1 & +1 & +1 & +1 & +1 \\
& 8 & +1 & -1 & -1 & -1 & +1 & +1 & +1 & +1 & +1 & +1 \\
\hline Number of & 9 & +1 & +1.682 & 0 & 0 & 0 & 0 & 0 & $2 \sqrt{2}$ & 0 & 0 \\
experi- & 10 & +1 & -1.682 & 0 & 0 & 0 & 0 & 0 & $2 \sqrt{2}$ & 0 & 0 \\
ments in & 11 & +1 & 0 & +1.682 & 0 & 0 & 0 & 0 & $\sqrt{2}$ & 0 \\
point start & 12 & +1 & 0 & -1.682 & 0 & 0 & 0 & 0 & 0 & $2 \sqrt{2}$ & 0 \\
$\left(^{*}\right)$ & 13 & +1 & 0 & 0 & +1.682 & 0 & 0 & 0 & 0 & $2 \sqrt{2}$ \\
& 14 & +1 & 0 & 0 & -1.682 & 0 & 0 & 0 & 0 & 0 & $2 \sqrt{2}$ \\
\hline Number of & 15 & +1 & 0 & 0 & 0 & 0 & 0 & 0 & 0 & 0 & 0 \\
experi- & 16 & +1 & 0 & 0 & 0 & 0 & 0 & 0 & 0 & 0 & 0 \\
ments in & 17 & +1 & 0 & 0 & 0 & 0 & 0 & 0 & 0 & 0 & 0 \\
the & 18 & +1 & 0 & 0 & 0 & 0 & 0 & 0 & 0 & 0 & 0 \\
planning & 19 & +1 & 0 & 0 & 0 & 0 & 0 & 0 & 0 & 0 & 0 \\
center & 20 & +1 & 0 & 0 & 0 & 0 & 0 & 0 & 0 & 0 & 0 \\
\hline
\end{tabular}

The mean results of measuring the spindle vibration amplitude of 20 experiments and each experiment were repeated 7 times as shown in Table 3 .

Table 3. The results the spindle vibration amplitude

\begin{tabular}{|c|c|c|c|c|c|}
\hline $\mathbf{N}^{\mathbf{0}}$ & $\overline{\boldsymbol{y}}$ & $\boldsymbol{s}_{\boldsymbol{i}}^{\mathbf{2}}$ & $\mathbf{N}^{\mathbf{0}}$ & $\overline{\boldsymbol{y}}$ & $\boldsymbol{s}_{\boldsymbol{i}}^{\mathbf{2}}$ \\
\hline 1 & 0.351 & 0.0004 & 11 & 0.398 & 0.0006 \\
\hline 2 & 0.581 & 0.0084 & 12 & 0.301 & 0.0014 \\
\hline 3 & 0.116 & 0.0007 & 13 & 0.224 & 0.0025 \\
\hline 4 & 0.525 & 0.002 & 14 & 0.176 & 0.0004 \\
\hline 5 & 0.31 & 0.0015 & 15 & 0.075 & 0.0002 \\
\hline 6 & 0.489 & 0.0021 & 16 & 0.07 & 0.0002 \\
\hline 7 & 0.09 & 0.0005 & 17 & 0.075 & 0.0001 \\
\hline 8 & 0.491 & 0.0022 & 18 & 0.07 & 0.0001 \\
\hline 9 & 0.278 & 0.0007 & 19 & 0.075 & 0.0001 \\
\hline 10 & 0.844 & 0.0158 & 20 & 0.07 & 0.0001 \\
\hline
\end{tabular}

\section{Results and discussion}

\subsection{The coefficients of regression equation}

With this Box-Hunter experimental model, the coefficients of regression equation were obtained by the results of experimental data and expressed by the following Eq. 1.

$$
\begin{aligned}
& y=0.0731-0.1597 x_{1}+0.0498 x_{2}+0.0208 x_{3} \\
& +0.0489 x_{1} x_{2}-0.0086 x_{13}+0.0104 x_{23}+ \\
& +0.1689 x_{1}^{2}+0.0943 x_{2}^{2}+0.0413 x_{3}^{2}
\end{aligned}
$$

\subsection{The testing of the individual regression coefficients}

After calculating the value of the coefficients of the regression equation, it is necessary to test their significance and eliminate the insignificant individual regression coefficients [14, 15]. The computational results are shown in Table 4. 
Table 4. Significance test of individual regression coefficients

\begin{tabular}{|c|c|c|c|c|c|}
\hline Tern & $\begin{array}{c}\text { Value of } \\
\text { Coefficient }\end{array}$ & $\begin{array}{c}\text { SE } \\
\text { coefficient }\end{array}$ & $\mathbf{T}$ & P-Value & \\
\hline $\mathrm{b}_{0}$ & 0.0731 & 0.01048 & 6.977 & 0.00 & \\
\hline $\mathrm{b}_{1}$ & -0.1597 & 0.006953 & -22.861 & 0.00 & \\
\hline $\mathrm{b}_{2}$ & 0.0498 & 0.006953 & 7.078 & 0.00 & \\
\hline $\mathrm{b}_{3}$ & 0.0208 & 0.006953 & 3.183 & 0.086 & Insignificant \\
\hline $\mathrm{b}_{12}$ & 0.0489 & 0.006769 & 5.517 & 0.00 & \\
\hline $\mathrm{b}_{13}$ & -0.0086 & 0.006769 & -0.812 & 0.436 & Insignificant \\
\hline $\mathrm{b}_{23}$ & 0.0104 & 0.006769 & 1.004 & 0.339 & Insignificant \\
\hline $\mathrm{b}_{11}$ & 0.1689 & 0.009085 & 24.920 & 0.00 & \\
\hline $\mathrm{b}_{22}$ & 0.0943 & 0.009085 & 13.873 & 0.00 & \\
\hline $\mathrm{b}_{33}$ & 0.0413 & 0.009085 & 6.064 & 0.00 & \\
\hline
\end{tabular}

In the Significance test table, $\mathrm{P}$ - value of less than 0.05 indicates that the model terms can be considered significant. Table 4 presented of Significance test table for regression equation coefficients. There are 3 coefficient $b_{3}, b_{13}$ and $b_{23}$ are not significant because its $\mathrm{P}$ value is more than 0.05 . We remove these coefficients, then we rewrite the matrix and recalculate the coefficients. Through the backward elimination process, the final quadratic models of response equation in terms of coded factors are presented as follows Eq. 2.

$$
\begin{aligned}
& y=0.0731-0.1597 x_{1}+0.0498 x_{2}+0.0489 x_{1} x_{2}+ \\
& +0.1689 x_{1}^{2}+0.0943 x_{2}^{2}+0.0413 x_{3}^{2}
\end{aligned}
$$

\subsection{Testing lack of fit in regression}

For testing lack of fit in regression, to perform the analysis of variance for Significance of regression is shown in Table 5

Table 5. Analysis of variance for Significance of regression

\begin{tabular}{|c|c|c|c|c|c|}
\hline Source & $\begin{array}{c}\text { Sum of } \\
\text { Squares }\end{array}$ & DF & $\begin{array}{c}\text { Mean } \\
\text { Square }\end{array}$ & F & $\begin{array}{c}\text { P- } \\
\text { Value }\end{array}$ \\
\hline Model & 0.8847 & 6 & 0.14746 & 68.94 & 0.00 \\
\hline $\begin{array}{c}\text { Residual } \\
\text { Error }\end{array}$ & 0.0278 & 13 & 0.00214 & & \\
\hline $\begin{array}{c}\text { Lack-of- } \\
\text { Fit }\end{array}$ & 0.027767 & 8 & 0.003471 & 462.78 & 0.00 \\
\hline $\begin{array}{c}\text { Pure } \\
\text { Error }\end{array}$ & 0.000038 & 5 & 0.000008 & & \\
\hline Total & 0.9125 & 19 & & & \\
\hline
\end{tabular}

The model was developed with $95 \%$ confidence interval. Because $\mathrm{F}_{\text {model }}=68.94>\mathrm{F}_{0.05,6,13}=2.92$ and $\mathrm{F}_{\mathrm{LOF}}=462.78>\mathrm{F}_{0.05,8,5}=4.82$. Also, note that the Pvalue for $F_{\text {model }}$ and $F_{\text {LOF }}$ (shown in Table 5) is considerably smaller than $\alpha=0.05$. The regression model is fitting well.

In the actual form, the regression equation shows the relation between the feed rate (s), cutting speed (n), cutting depth (t) and the spindle vibration amplitude (A) of the CNC machine are presented as follows Eq. 3.

$$
\begin{aligned}
& A=1.993-20.212 .10^{-5} n-0.7807 t- \\
& -3.304 .10^{-4} s+0.0166 .10^{-3} n t+0.0676 .10^{-7} n^{2} \\
& +0.262 t^{2}+1.652 .10^{-7} s^{2}
\end{aligned}
$$

\subsection{Evaluation of experimental results}

In the milling process, the machining parameters adopting the spindle speed, the feed rate, and the depth of cut were chosen as the three factors so as to investigate the influences on the vibration amplitude. The influences of machining parameters on the performance of the vibration amplitude have been analyzed, which is based on the above proposed mathematical model.
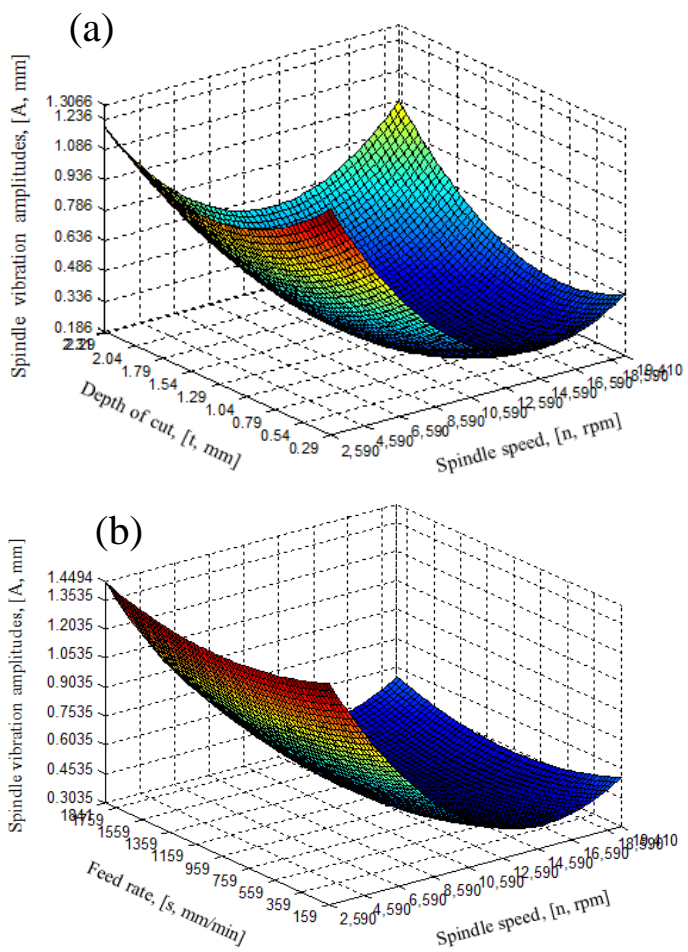


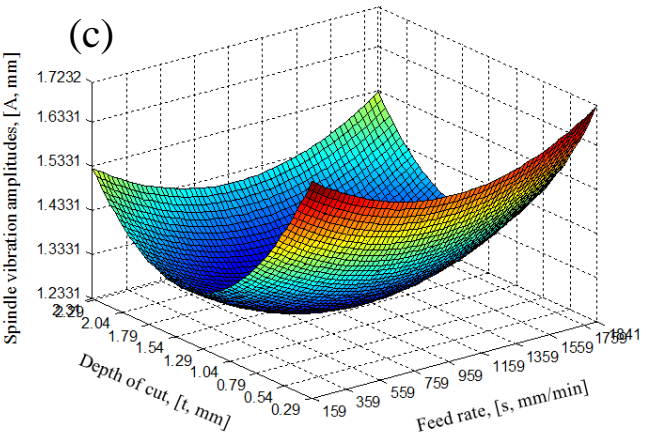

Figure 3. (a) Effect of $\mathrm{n}$ and $\mathrm{t}$ on the spindle vibration amplitude; (b) Effect of $\mathrm{n}$ and $\mathrm{s}$ on the spindle vibration amplitude and (c) Effect of $t$ and $s$ on the spindle vibration amplitude

In graphs Fig. 3 shows the relationship between the feed rate, cutting speed, cutting depth and the spindle vibration amplitude of the CNC milling machine. It can be seen that the tendency of spindle vibration amplitudes slightly decreases with an increase of spindle speed. Increasing the spindle speed promotes the rotation stability of spindle head, which results in suppressing the vibration amplitude. As seen above, the spindle vibration amplitudes obviously increase with increasing the feed rate.

In the cutting process, the resistance force acting on the cutting tool is mainly generated by the status of feed rate and depth of cut. The increase of cutting depth and feed rate causes the increase in the resistance force at the tooltip and cutting feed direction, which excites more vibration appearance. It can be obviously seen that the spindle vibration amplitudes increase with increasing the value of cutting depth and feed rate. As the results of analysis discussed above, the spindle vibration amplitudes are principally influenced by the spindle speed, feed rate and cutting depth.

In Fig. 3, the local reasonable cutting parameters valued (within the scope of the survey) so that the spindle vibration amplitudes is minimal as follows: $\mathrm{n}=$ $14280 \mathrm{rpm}, \mathrm{s}=1043 \mathrm{~mm} / \mathrm{min}$ and $\mathrm{t}=1.043 \mathrm{~mm} \Rightarrow$ spindle vibration amplitude: $A_{\min }=0.017 \mathrm{~mm}$.

\section{The machine structure using the bolt joint}

Machine structure using a bolt joint and an experimental setup of the spindle head of the CNC milling machine is shown in Fig. 4.

With the same cutting parameters as above, the results of measuring the spindle vibration of 20 experiments and each experiment were repeated 7 times as shown in Table 6.

The regression equation shows the relation between the feed rate (s), cutting speed $(\mathrm{n})$, cutting depth $(\mathrm{t})$ and the spindle vibration amplitude (A) of the milling machine are presented as follows Eq. 4

$$
\begin{aligned}
& A=1.993-20.212 .10^{-5} n-0.7807 t- \\
& -3.304 .10^{-4} s+0.0166 .10^{-3} n t+0.0676 .10^{-7} n^{2}+ \\
& +0.262 t^{2}+1.652 .10^{-7} s^{2}
\end{aligned}
$$

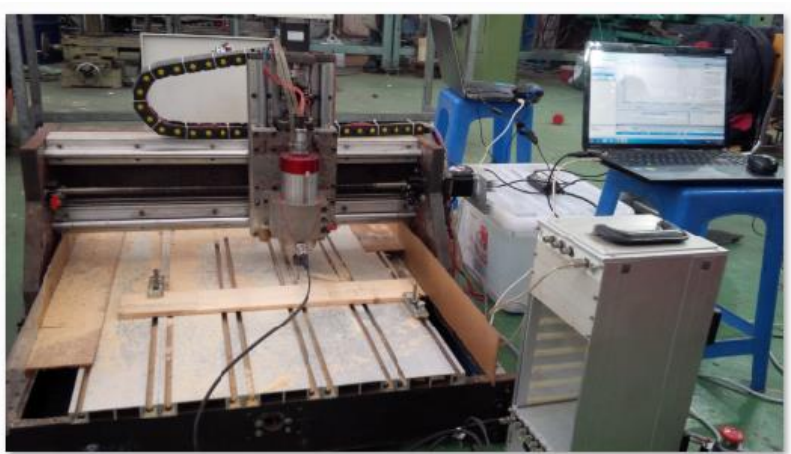

Figure 4. Machine structure using a bolt joint and Experimental Setup

Table 6. Experimental results

\begin{tabular}{|c|c|c|c|c|c|}
\hline $\mathbf{N}^{\mathbf{0}}$ & $\overline{\boldsymbol{y}}$ & $\boldsymbol{s}_{\boldsymbol{i}}^{\mathbf{2}}$ & $\mathbf{N}^{\mathbf{0}}$ & $\overline{\boldsymbol{y}}$ & $\boldsymbol{s}_{\boldsymbol{i}}^{\mathbf{2}}$ \\
\hline 1 & 0.355 & 0.0014 & 11 & 0.0097 & 0.0006 \\
\hline 2 & 0.576 & 0.0146 & 12 & 0.0056 & 0.0014 \\
\hline 3 & 0.121 & 0.0004 & 13 & 0.001 & 0.0025 \\
\hline 4 & 0.576 & 0.0059 & 14 & 0.0016 & 0.0004 \\
\hline 5 & 0.34 & 0.0006 & 15 & 0.0001 & 0.0002 \\
\hline 6 & 0.541 & 0.0211 & 16 & 0.069 & 0.0001 \\
\hline 7 & 0.098 & 0.0005 & 17 & 0.067 & 0.0001 \\
\hline 8 & 0.575 & 0.0119 & 18 & 0.07 & 0.0001 \\
\hline 9 & 0.223 & 0.0002 & 19 & 0.075 & 0.0001 \\
\hline 10 & 0.862 & 0.0133 & 20 & 0.072 & 0.0001 \\
\hline
\end{tabular}

The comparison results of spindle vibration amplitude for two different machine structure types are the structures using the welded joint and the bolt joint.The results show that the spindle head vibration amplitude of the machine using the bolt joint is larger than the spindle head vibration amplitude of the machine using the weld joint.

\section{Conclusions}

The paper presents the effect of the cutting parameters such as feed rate, cutting speed, and cutting depth on the vibration amplitude of the spindle when machined on CNC milling machine by experimental design method (DOE). Using the Box-Hunter method of experimentation to construct a second-order regression equation representing the relationship between the cutting parameters and the vibration amplitude of the spindle to survey the effect of the cutting parameters on the spindle vibration in machining process. The results show that as the spindle speed increases, the rotational 
stability of the spindle head is promoted, which reduces the vibrations amplitude and the spindle vibration amplitudes increase with increasing the value of cutting depth and feed rate to cause the unstability of cutting process and exhibit the result of the worst machined surface. In addition within the scope of survey also identified the most appropriate cutting parameters for machining on CNC wood milling machine.

The comparison results of spindle vibration amplitude for two different machine structure types are the structures using the welded joint and the bolt joint show that the spindle head vibration amplitude of the machine using the bolt joint is larger than the spindle head vibration amplitude of the machine using the weld joint

Acknowledgement: This research is funded by Vietnam National University - Ho Chi Minh City (VNU-HCM) under grant number B2016-20-04.

\section{References}

1. E. Bamberg, Principles of rapid machine design, Massachusetts Institute of Technology, (2000).

2. S.Y. Kassab, Y.K. Khoshnaw, Engineering and technology 25 879-889 (2007).

3. S. Zahoor, N.A. Mufti, M.Q. Saleem, M.P. Mughal, M.A.M. Qureshi, The International Journal of Advanced Manufacturing Technology 89 36713679 (2017) .
4. M. Sayuti, A.A. Sarhan, M. Hamdi, The International Journal of Advanced Manufacturing Technology 67 833-849 (2013).

5. G. Mahesh, S. Muthu, S. Devadasan, The International Journal of Advanced Manufacturing Technology 77 369-381 (2015).

6. G. Zhang, J. Li, Y. Chen, Y. Huang, X. Shao, M. Li, The International Journal of Advanced Manufacturing Technology 75 1357-1370 (2014).

7. S.S. Baraskar, S. Banwait, S. Laroiya, Materials and Manufacturing Processes 28 348-354 (2013).

8. C.-C. Chen, N.-M. Liu, K.-T. Chiang, H.-L. Chen, The International Journal of Advanced Manufacturing Technology 63 797-815 (2012).

9. B. Kilundu, P. Dehombreux, X. Chiementin, Mechanical Systems and Signal Processing 25 400415 (2011).

10. N. Kusuma, M. Agrawal, P. Shashikumar, (2014).

11. N. Zeelanbasha, V. Senthil, B. Sharon Sylvester, Metalurgija 57 121-124 (2018) .

12. D. Dimla Sr, Journal of materials processing technology 155 1708-1715 (2004).

13. M. Thomas, Y. Beauchamp, A. Youssef, J. Masounave, Computers \& industrial engineering 31 637-644 (1996).

14. D.C. Montgomery, Design and analysis of experiments, John wiley \& sons, (2017).

15. H.L. Nguyen, Experimental Design, National University publisher HCMC, Viet Nam, (2014). 